\title{
In vitro activity of the hydroethanolic extract and biflavonoids isolated from Selaginella sellowii on Leishmania (Leishmania) amazonensis
}

\author{
Yasmin Silva Rizk', Alice Fischer ${ }^{2}$, Marillin de Castro Cunha ${ }^{3}$, Patrik Oening Rodrigues ${ }^{4}$, \\ Maria Carolina Silva Marques ${ }^{5}$, Maria de Fátima Cepa Matos ${ }^{3}$, Mônica Cristina Toffoli Kadrí, \\ Carlos Alexandre Carollo², Carla Cardozo Pinto de Arruda ${ }^{1 /+}$ \\ ${ }^{1}$ Laboratório de Parasitologia Humana ${ }^{2}$ Laboratório de Farmacognosia ${ }^{3}$ Laboratório de Biologia Molecular e Culturas Celulares \\ ${ }^{4}$ Laboratório de Tecnologia Farmacêutica ${ }^{5}$ Laboratório de Microbiologia ${ }^{6}$ Laboratório de Biofisiofarmacologia, \\ Centro de Ciências Biológicas e da Saúde, Universidade Federal de Mato Grosso do Sul, Campo Grande, MS, Brasil
}

This study is the first phytochemical investigation of Selaginella sellowii and demonstrates the antileishmanial activity of the hydroethanolic extract from this plant (SSHE), as well as of the biflavonoids amentoflavone and robustaflavone, isolated from this species. The effects of these substances were evaluated on intracellular amastigotes of Leishmania (Leishmania) amazonensis, an aetiological agent of American cutaneous leishmaniasis. SSHE was highly active against intracellular amastigotes [the half maximum inhibitory concentration $\left(I C_{50}\right)=20.2 \mu \mathrm{g} / \mathrm{mL}$ ]. Fractionation of the extract led to the isolation of the two bioflavonoids with the highest activity: amentoflavone, which was about 200 times more active $\left(I C_{50}=0.1 \mu \mathrm{g} / \mathrm{mL}\right)$ and less cytotoxic than SSHE $\left(I C_{50}=2.2 \mathrm{and} 3 \mu \mathrm{g} / \mathrm{mL}\right.$, respectively on NIH/3T3 and J774.A1 cells), with a high selectivity index (SI) (22 and 30), robustaflavone, which was also active against $\mathrm{L}$. amazonensis $\left(I C_{50}=2.8 \mu \mathrm{g} / \mathrm{mL}\right)$, but more cytotoxic, with $I C_{50}=25.5 \mu \mathrm{g} / \mathrm{mL}(\mathrm{SI}=9.1)$ on $N I H / 3 T 3$ cells and $I C_{50}=3.1 \mu \mathrm{g} / \mathrm{mL}(S I=1.1)$ on J774.A1 cells. The production of nitric oxide $(N O)$ was lower in cells treated with amentoflavone (suggesting that NO does not contribute to the leishmanicidal mechanism in this case), while NO release was higher after treatment with robustaflavone. S. sellowii may be a potential source of biflavonoids that could provide promising compounds for the treatment of cutaneous leishmaniasis.

Key words: cutaneous leishmaniasis - amentoflavone - robustaflavone - antileishmanial activity

Leishmaniases are a group of infectious diseases caused by protozoan parasites of the genus Leishmania transmitted by the bite of sandflies. American cutaneous leishmaniasis (ACL) is the cutaneous form of the disease in the New World, with clinical manifestations ranging from skin to mucosal lesions, including widespread and diffuse forms (Gontijo \& Carvalho 2003, Reithinger et al. 2007). The cutaneous diffuse manifestation is associated, in Brazil, with Leishmania (Leishmania) amazonensis, a form in which anergic individuals develop numerous parasite-rich nodules. A lesion develops at the site of the insect bite and evolves slowly, with multiple non-ulcerated nodules appearing in large extensions of the skin, usually with poor response to treatment (Grimaldi Jr \& Tesh 1993).

The first-choice drugs for the treatment of leishmaniasis are the pentavalent antimonials $\left(\mathrm{Sb}^{\mathrm{v}}\right)$. Amphotericin B and pentamidine are used as alternative therapeutic options. However, all of these drugs have important limitations as to the safety of use, presenting relevant toxicity and a high frequency of side effects (Croft \& Coombs 2003, Sundar \& Chatterjee 2006, Oliveira et al.

doi: 10.1590/0074-0276140312

Financial support: CNPq, FUNDECT

+ Corresponding author: carla.arruda@ufms.br

Received 25 August 2014

Accepted 27 November 2014
2011). The antimonials require long-term use and parenteral administration, resulting in treatment failure and resistant parasites (Sundar et al. 2000), facts which reinforce the urgent need for new therapeutic agents.

Recently, much effort have been applied to the development of antileishmanial compounds, either naturally or synthetically obtained (Monzote 2009). Natural products are a great source of new biologically active compounds that can be used directly or with structural modifications designed to improve their activities and/or reduce their toxicity (Brahmachari 2011).

The genus Selaginella (Selaginellaceae) contains about 750 species, distributed mainly in tropical areas (Jeremy 1990). Many of them are used in traditional medicine in countries like India, China and Brazil (Sah et al. 2005, Zheng et al. 2011, Santos et al. 2012). Several metabolites have been isolated in the genus, such as alkaloids (Wang et al. 2009), lignans and phenylpropanoids (Lin et al. 1994) and mainly biflavonoids (Lin et al. 2000). Studies have explored the biological activities of compounds present in their species, including anticancer, antifungal (Mishra et al. 2011) and antiviral activities (Ma et al. 2001). Kunert et al. (2008) observed antileishmanial activity in biflavonoids present in Selaginella bryopteris.

Selaginella sellowii is widely found in the Brazilian Pantanal wetlands (Assis \& Labiak 2009), but there are no descriptions of its compounds and their respective biological activities. The aim of this study was to evaluate the activity of the hydroethanolic extract and of the biflavonoids (amentoflavone and robustaflavone) isolated from S. sellowii on intracellular amastigotes of L. amazonensis. 


\section{MATERIALS AND METHODS}

Plant material - S. sellowii Hieron (Selaginellales: Selaginellaceae) was collected in June 2009 in the state of Mato Grosso do Sul, Brazil. The plant was identified by Dr Arnildo Pott of the Botany Laboratory, Centre for Biological and Health Sciences (CCBS) of the Federal University of Mato Grosso do Sul (UFMS) and voucher material was deposited in the CG/MS Herbarium under registration 27218 (license CGEN/MMA 010273/2013-1).

Plant extraction and isolation - The whole dried pulverised plant was submitted to a pressurised fluid extractor (Dionex, model ASE 150) equipped with an extraction cartridge $(100 \mathrm{~mL})$. The following parameters were repeated three times: temperature of $130^{\circ} \mathrm{C}$, pressure of 1,500 psi, static extraction time of $4 \mathrm{~min}, 150 \%$ volume wash and three cycles of extraction. Plant material $(90.0 \mathrm{~g})$ was first extracted with dichloromethane to remove apolar compounds, followed by a mixture of ethyl acetate:methanol (8:2) and finally ethanol:water (7:3). The latter extraction cycles were concentrated in a rotary evaporator, yielding a hydroethanolic extract denominated SSHE. The yield was $10 \%(\mathrm{w} / \mathrm{w})$. SSHE $(2.0$ g) was chromatographed on a Sephadex LH-20 column and eluted with methanol $(\mathrm{MeOH}) ; 102$ fractions of 20 $\mathrm{mL}$ were collected. The obtained fractions were grouped after thin-layer chromatography on silica gel 60 plates (Merck), eluted with chloroform:methanol (9:1 and 8.5:1.5) and the revealed with NP/PEG. Fractions 52-63 (14.8 $\mathrm{mg}$ ) were grouped, obtaining the compound amentoflavone (1). Fractions 64-101 (1 mg) were identified as robustaflavone (2) (Fig. 1).

Structural elucidation - The compounds were identified by ${ }^{1} \mathrm{HNMR},{ }^{13} \mathrm{C}$ NMR and DEPT-135 ${ }^{\circ}$ Bruker $(300 / 75$ $\mathrm{MHz}$, DPX-300 diluted in deuterated dimethyl sulfoxide (DMSO) (Merck, Germany). Data for mass spectrometry<smiles></smiles>

Fig. 1: compounds isolated from Selaginella sellowii: amentoflavone (1) and robustaflavone (2). and tandem mass spectrometry were obtained in high resolution (ESI-TOF micrOTOF II, Bruker Daltonics) with positive ionisation mode. The presence of amentoflavone and robustaflavone were confirmed by comparison with literature spectra (Agrawal \& Bansal 1989).

Liquid chromatography - SSHE was analysed quantitatively $(500 \mu \mathrm{g} / \mathrm{mL})$ for high-performance liquid chromatography (HPLC) with diode array detector (DAD) using a liquid chromatograph model LC-20AD coupled with a DAD (model SPD-M20A, Shimadzu), operating at a wavelength of $325 \mathrm{~nm}$ and manual injector with 20 $\mu \mathrm{L}$ loop sampling. A reversed phase octadecyl Shimadzu Shim-pack PREP-ODS (H) kit (250 mm x $4.6 \mathrm{~mm}, 5 \mu \mathrm{m})$ and guard column (4 cm x $3 \mathrm{~mm})$ with the same stationary phase were used for separation. The mobile phase consisted of $\mathrm{A}\left(\mathrm{H}_{2} \mathrm{O}\right)$ and $\mathrm{B}(\mathrm{MeOH})$, both with $1 \%$ acetic acid, using a linear gradient system: 0.01-10 $\min (25 \% \mathrm{~B}), 10-25$ $\min (100 \% \mathrm{~B}), 25-30 \mathrm{~min}(100 \% \mathrm{~B})$ and $30-45 \min (25 \%$ B). The flow rate was $0.8 \mathrm{~mL} / \mathrm{min}$. The chromatographic data were analysed on a computer with the LCsolution operating system (Shimadzu). The solvents were HPLC grade (Vetec) and ultrapure water (Millipore Inc).

Parasites - A standard strain of Leishmania (L.) amazonensis (IFLA/BR/1967/PH8) was used for in vitro tests. Amastigote forms were routinely isolated from BALB/c mice's cutaneous lesions and maintained as promastigotes at $25^{\circ} \mathrm{C}$ in Schneider's Insect Medium (Sigma-Aldrich), supplemented with $20 \%$ foetal calf serum (FCS) (Cultilab) and $140 \mu \mathrm{g} / \mathrm{mL}$ gentamicin (Sigma-Aldrich).

Animals - Female BALB/c mice aged six weeks were used to obtain resident peritoneal macrophages used in the tests. The animals were obtained from the central animal facility of the CCBS/UFMS in good health and free of common rodent infections or parasites, maintained in individually ventilated cages equipped with mini-isolators, fed a balanced feed (Nuvilab CR-1, Nuvital ${ }^{\circledR}$ ) with free access to water. This study received approval from the local Animal Experimentation Ethical Committee (CEUA/UFMS) under protocol 431/2012.

Antileishmanial activity - Peritoneal macrophages from BALB/c mice were isolated after rinsing with RPMI-1640 medium (Sigma) and placed (1 x 105 cells/ well) in a 24-well plate in RPMI-1640 medium (Sigma), supplemented with 10\% FCS (Cultilab) and $140 \mu \mathrm{g} / \mathrm{mL}$ gentamicin (Sigma). After $1 \mathrm{~h}$ incubation at $37^{\circ} \mathrm{C}$ in $5 \%$ $\mathrm{CO}_{2}$, cells were infected with $L$. amazonensis promastigotes ( 1 x $10^{6}$ cells/well) and subsequently incubated at $35^{\circ} \mathrm{C}$ for $4 \mathrm{~h}$. SSHE was added at concentrations of $50-12.5 \mu \mathrm{g} / \mathrm{mL}$. The cells were incubated at $35^{\circ} \mathrm{C}$ in $5 \%$ $\mathrm{CO}_{2}$, fixed and stained with Giemsa after 24, 48 and 72 h. Amentoflavone and robustaflavone were added at different concentrations and the cells stained after $72 \mathrm{~h}$ of treatment. Untreated infected cells were used as negative control. Amphotericin B (Sigma) was used as a positive control and analysed after $24 \mathrm{~h}$. The percentage of infected macrophages and the total number of amastigotes were determined by counting 200 cells in each six replicates. The infection index was determined by multiplying the percentage of macrophages that had at least 
one intracellular parasite by the mean of amastigotes per macrophage (Paladi et al. 2012). A non-linear doseresponse regression curve was used to calculate the half maximum inhibitory concentration $\left(\mathrm{IC}_{50}\right)$.

Nitric oxide (NO) evaluation - NO production by $L$. amazonensis infected cells treated as described in the previous item was evaluated. One hundred microlitres of the supernatants were collected and incubated with an equal volume of Griess reagent ( $1 \%$ sulfanilamide $/ 0.1 \%$ naphthalene diamine dihydrochloride $/ 2.5 \% \mathrm{H}_{3} \mathrm{PO}_{4}$ ) for $10 \mathrm{~min}$ at room temperature for the quantification of the nitrite accumulation (Ding et al. 1988). Absorbance was determined at $540 \mathrm{~nm}$. The conversion of absorbance to $\mu \mathrm{M}$ of $\mathrm{NO}_{2}{ }^{-}$was performed by comparing the samples to a standard curve obtained with known concentrations $(1-10 \mu \mathrm{M})$ of sodium nitrite diluted in RPMI medium.

Cytotoxicity assay - Murine macrophages (J774.A1) and fibroblast cells (NIH/3T3) purchased from the Rio de Janeiro Cell Bank (Brazil) were treated with SSHE and isolated compounds at four concentrations from $0.25-250 \mu \mathrm{g} / \mathrm{mL}$ in triplicates for estimating $\mathrm{IC}_{50}$. The plates were incubated with the test substances for $48 \mathrm{~h}$ at $37^{\circ} \mathrm{C}$ and $5 \% \mathrm{CO}_{2}$ amphotericin $\mathrm{B}$ (Sigma) was used as reference drug $(0.025-25 \mu \mathrm{g} / \mathrm{mL}$ ). DMSO (Vetec) was used as a negative control at the concentration used to solubilise higher concentrations of test compounds.

Cell viability was determined using sulforhodamine B (SRB) assay (Skehan et al. 1990). Briefly, the cells were fixed with $100 \mu \mathrm{L}$ of ice-cold $20 \%$ trichloroacetic acid (Sigma) and incubated at $4^{\circ} \mathrm{C}$ for $30 \mathrm{~min}$. The supernatant was then discarded and the plates were washed five times with tap water. The cells were stained for 30 min with $0.1 \%$ SRB in $1 \%$ acetic acid $(50 \mu \mathrm{L} /$ well) (Sig$\mathrm{ma}$ ) and subsequently washed four times with $1 \%$ acetic acid to remove the unbound dye. The plates were airdried and the protein-bound dye was solubilised with $100 \mu \mathrm{L} 10 \mathrm{mM}$ Trizma buffer (Sigma). The plates were shaken for $10 \mathrm{~min}$ on a shaker and the resulting optical density was read in a multiwell plate reader at $540 \mathrm{~nm}$. The growth percentage of each test sample was calculated as described by Monks et al. (1991). A non-linear dose-response regression curve was used to calculate $\mathrm{IC}_{50}$. The selectivity index (SI) was calculated according to Medeiros et al. (2011).
Statistical analysis - NO evaluation and the infection index were expressed as the mean \pm standard deviation and the data were analysed using the Student's $t$ test. Differences were considered significant at $\mathrm{p}<0.05$ (represented by asterisks).

\section{RESULTS AND DISCUSSION}

SSHE was tested against intracellular amastigotes by evaluating the kinetics of infection at 24, 48 and 72 h. Our results demonstrated a dose-dependent inhibition of the proliferation of intracellular amastigotes with highest activity registered $72 \mathrm{~h}$ after extract addition. At that point, the infection index had decreased from 51.6$96.5 \%$, from the lowest to the highest concentration tested (Fig. 2). The IC that reduced $50 \%$ of the intracellular forms of L. amazonensis $\left(\mathrm{IC}_{50}\right)$ was $20.2 \mu \mathrm{g} / \mathrm{mL}$ with no cytotoxicity to the mammalian cells tested (Table).

SSHE was considered active according to Claudino et al. (2013). Thus their constituents were characterised in order to identify the compounds responsible for the activity. Amphotericin B was used as a reference drug and resulted in $\mathrm{IC}_{50}$ value of $0.03 \mu \mathrm{g} / \mathrm{mL}$ against L. amazonensis (Table). Despite its high activity and selectivity, the clinical treatment with amphotericin B is still high-

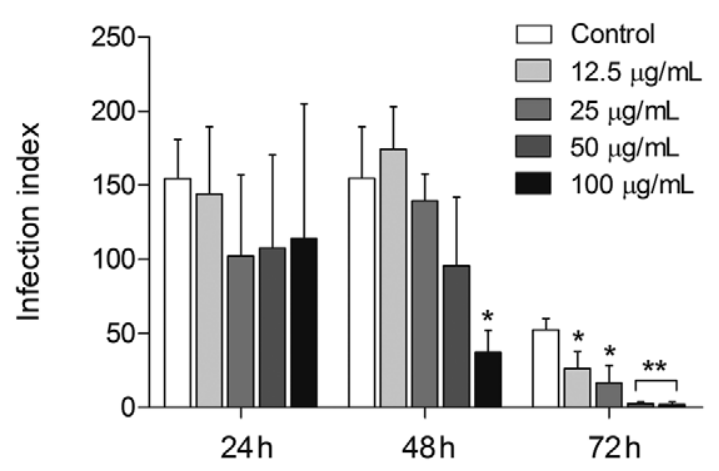

Fig. 2: antileishmanial activity of the hydroethanolic extract from $\mathrm{Se}$ laginella sellowii (SSHE) on intracellular amastigotes. Peritoneal macrophages were infected with Leishmania amazonensis and treated with different concentrations of SSHE. Infection index was calculated 24, 48 and $72 \mathrm{~h}$ after treatment. Bars represent the mean \pm standard deviation of quadruplicates. $\mathrm{p}<0.01\left(^{*}\right)$ and $\mathrm{p}<0.0001(* *)$ for the different concentrations compared to untreated cells (control) (Student's $t$ test).

TABLE

Antileishmanial activity and cytotoxicity of hydroethanolic extract (SSHE) and biflavonoids isolated from Selaginella sellowii

\begin{tabular}{|c|c|c|c|c|c|}
\hline \multirow[b]{2}{*}{ Test sample } & \multirow{2}{*}{$\begin{array}{c}\text { Intracellular amastigotes } \\
\mathrm{IC}_{50} \\
\mu \mathrm{g} / \mathrm{mL}(\mu \mathrm{M})\end{array}$} & \multicolumn{2}{|c|}{ NIH/3T3 } & \multicolumn{2}{|c|}{ J774.A1 } \\
\hline & & $\begin{array}{c}\mathrm{IC}_{50} \\
\mu \mathrm{g} / \mathrm{mL}^{(}(\mu \mathrm{M})\end{array}$ & SI & $\begin{array}{c}\mathrm{IC}_{50} \\
\mu \mu \mathrm{g} / \mathrm{mL}(\mu \mathrm{M})\end{array}$ & SI \\
\hline SSHE & 20.2 & 246.4 & 12.2 & 166.3 & 8.2 \\
\hline Amentoflavone & $0.1(0.2)$ & $2.2(4.0)$ & 22 & $3(5.5)$ & 30 \\
\hline Robustaflavone & $2.8(5.3)$ & $25.5(47.4)$ & 9.1 & $3.1(5.7)$ & 1.1 \\
\hline Amphotericin B & $0.03(0.035)$ & $2.2(2.2)$ & 73 & $4.3(4.7)$ & 143.3 \\
\hline
\end{tabular}

$\mathrm{IC}_{50}$ : half maximum inhibitory concentration. SI (selectivity index) $=\mathrm{IC}_{50}$ mammalian cell $/ \mathrm{IC}_{50}$ amastigotes $(\mu \mathrm{g} / \mathrm{mL})$. 
ly toxic, costly and associated with cases of resistance (Freitas-Júnior et al. 2012), making the search for a new antileishmanial drug relevant.

The analysis of ultraviolet spectra of SSHE compounds revealed the presence of phenylpropanoids (Silverstein et al. 2007) and biflavonoids (Mabry et al. 1970) (Fig. 3). The fractionation led to the isolation of two biflavonoids described in the genus Selaginella: amentoflavone (Ma et al. 2001, Zhang et al. 2011) and robustaflavone (Lin et al. 2000, Zhang et al. 2011).

The ${ }^{13} \mathrm{C}$ NMR profiles of the compounds (1) and (2) were consistent with those reported previously for amentoflavone and robustaflavone (Agrawal \& Bansal 1989). The mass spectrum of (1) exhibited $\mathrm{m} / \mathrm{z} 539,0973$ $\left[\mathrm{M}^{+} \mathrm{H}\right]^{+}$and fragments which included $\mathrm{m} / \mathrm{z} 497,403,347$, $335,283,153$ and 121, characteristic of amentoflavone (Zhang et al. 2011). Compound (2) exhibited a mass spectrum with $\mathrm{m} / \mathrm{z} 539,0956\left[\mathrm{M}^{+} \mathrm{H}\right]^{+}$and fragments $\mathrm{m} / \mathrm{z}$ $521,465,387,283,270,153$ and 121, characteristic of robustaflavone (Zhang et al. 2011).

Amentoflavone shows various biological activities such as antiviral (Ma et al. 2001), antifungal (Jung et al. 2006), antioxidant (Sakthivel \& Guruvayoorappan 2013) and anti-inflammatory (Oh et al. 2013). Robustaflavone is described as a potent inhibitor of hepatitis B virus replication (Zembower et al. 1998). Furthermore, both biflavonoids are suggested for the development of promising anti-dengue drugs (Coulerie et al. 2013) and antielastase agents (Xu et al. 2009).

Once the highest activity was found $72 \mathrm{~h}$ after the treatment with SSHE, the isolates were evaluated at that point. Purification resulted in compounds with even higher activity. Treatment of intracellular amastigotes at all concentrations tested of amentoflavone caused a significant decrease $(p<0.0001)$ in the infection index when compared to the control, with a reduction greater than $90.6 \%$, reaching almost $100 \%$ at the highest concentration $(3 \mu \mathrm{g} / \mathrm{mL})$ (Fig. 4A). Amentoflavone was about 200 times more potent than SSHE $\left(\mathrm{IC}_{50}=0.1 \mu \mathrm{g} /\right.$ $\mathrm{mL}$ ). The excellent antileishmanial activity of amentoflavone obtained in our study is in agreement with those obtained by Oubada et al. (2014), who observed the effects on L. amazonensis intracellular amastigotes $48 \mathrm{~h}$ after the aforementioned treatment. Amentoflavone was not active on axenic amastigotes of Leishmania donovani (Weniger et al. 2006, Kunert et al. 2008) and showed poor activity on promastigotes of the same species (Camacho et al. 2000). Therefore, the antileishmanial action of this compound may be mediated by the host cell. This fact, coupled with the delayed action of SSHE (72 h), leads us to consider the compound as a pro-drug, which needs to be metabolised by the cell to exert its effect.

Robustaflavone also showed antileishmanial activity in a dose-dependent way, with a reduction of the infection index reaching $90.8 \%(12.5 \mu \mathrm{g} / \mathrm{mL})$ (Fig. 4B). Robustaflavone was less active than amentoflavone, with an $\mathrm{IC}_{50}$ value of $2.8 \mu \mathrm{g} / \mathrm{mL}$. Despite being considered as active $\left(\mathrm{IC}_{50}<10 \mu \mathrm{g} / \mathrm{mL}\right)$, the compound showed some cytotoxicity on mammalian cells, with an SI below 10 (Lenta et al. 2007), as shown in Table.

Activation of macrophages was investigated by the NO release. NO production was significantly increased $(p<0.05)$ after treatment with the highest concentration of SSHE $(100 \mu \mathrm{g} / \mathrm{mL})$ (Fig. 5A). NO production by peritoneal macrophages treated with amentoflavone was significantly lower at the concentrations of $1.5 \mu \mathrm{g} / \mathrm{mL}$ (p $<0.05)$ and $0.75 \mu \mathrm{g} / \mathrm{mL}(\mathrm{p}<0.01)$, compared to untreated infected cells (Fig. 5B). This may be due to the antioxidant properties of amentoflavone. Banerjee et al. (2002) observed the inhibition of inducible NO synthase (iNOS) protein expression by amentoflavone. In addition, Woo et al. (2005) demonstrated the inhibitory effect of amen-

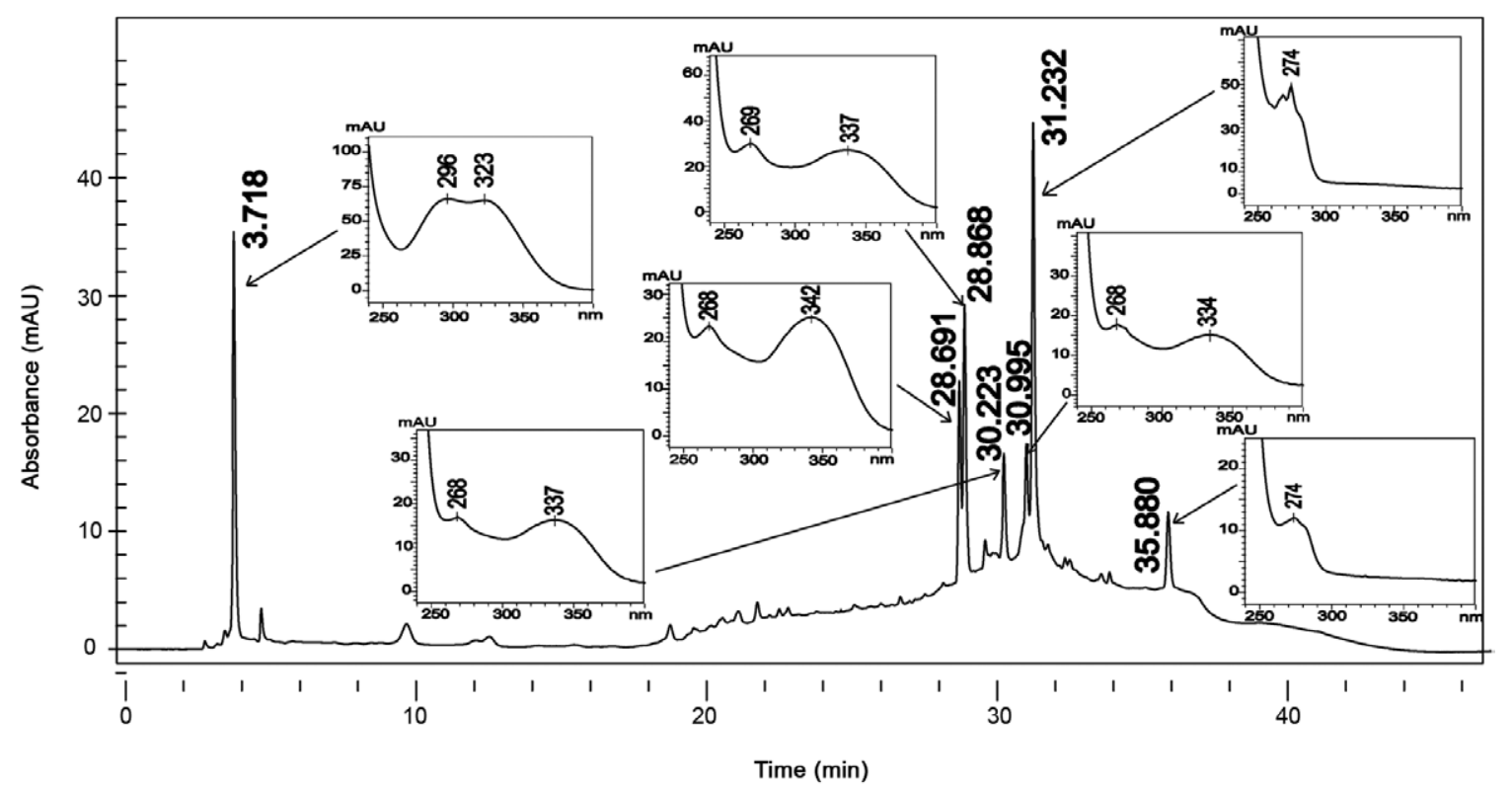

Fig. 3: chromatographic profile at $270 \mathrm{~nm}$ and ultraviolet absorption spectra $(240-400 \mathrm{~nm})$ of the hydroethanolic extract from Selaginella sellowii. 

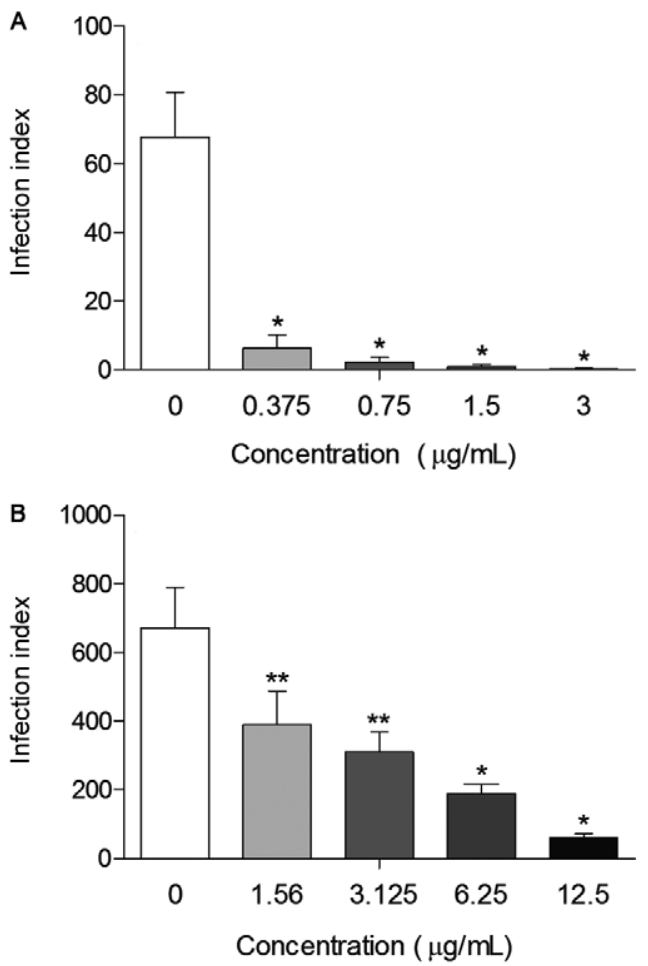

Fig. 4: antileishmanial activity of amentoflavone (A) and robustaflavone (B) on intracellular amastigotes. Peritoneal macrophages were infected with Leishmania amazonensis and treated with different concentrations of the compounds. Infection index was calculated 72 $\mathrm{h}$ after treatment. Bars represent the mean \pm standard deviation of six replicates. $\mathrm{p}<0.01\left({ }^{* *}\right)$ and $\mathrm{p}<0.0001(*)$ for the different concentrations compared to untreated cells (control) (Student's $t$ test).

toflavone on NO production induced by lipopolysaccharide, which prevents the activation of NF- $\mathrm{KB}$, the gene responsible for transcription of iNOS. They suggest, therefore, that the destruction mechanism of intracellular amastigotes by this biflavonoid should not be directly associated with increased release of NO. Amentoflavone could have a direct action on the parasites and/or influence over other cytotoxic mechanisms for intracellular pathogens. Defense mechanisms independent of NO release can be promising in cases of ACL associated with strains of L. amazonensis and Leishmania braziliensis resistant to NO, as described by Giudice et al. (2007), who demonstrated that the resistance to NO is directly related to lesion size and severity of the disease.

In contrast, robustaflavone had increased the NO release by infected macrophages at the highest concentration tested (Fig. 5C). In fact, Yang et al. (2006) demonstrated that robustaflavone isolated from Selaginella tamariscina did not affect the expression of iNOS. In the same study, this effect was compared with another isolated biflavonoid called sumaflavone, which, as amentoflavone, has inhibited iNOS and decreased NO levels. The authors also suggest the difference in inhibitory potential of NO due to differences in the location of the $\mathrm{C}-\mathrm{C}$ bond in the compounds, i.e., IC3'-IIC8" in amentoflavone/sumaflavone and IC3'-IIC6" in robustaflavone.
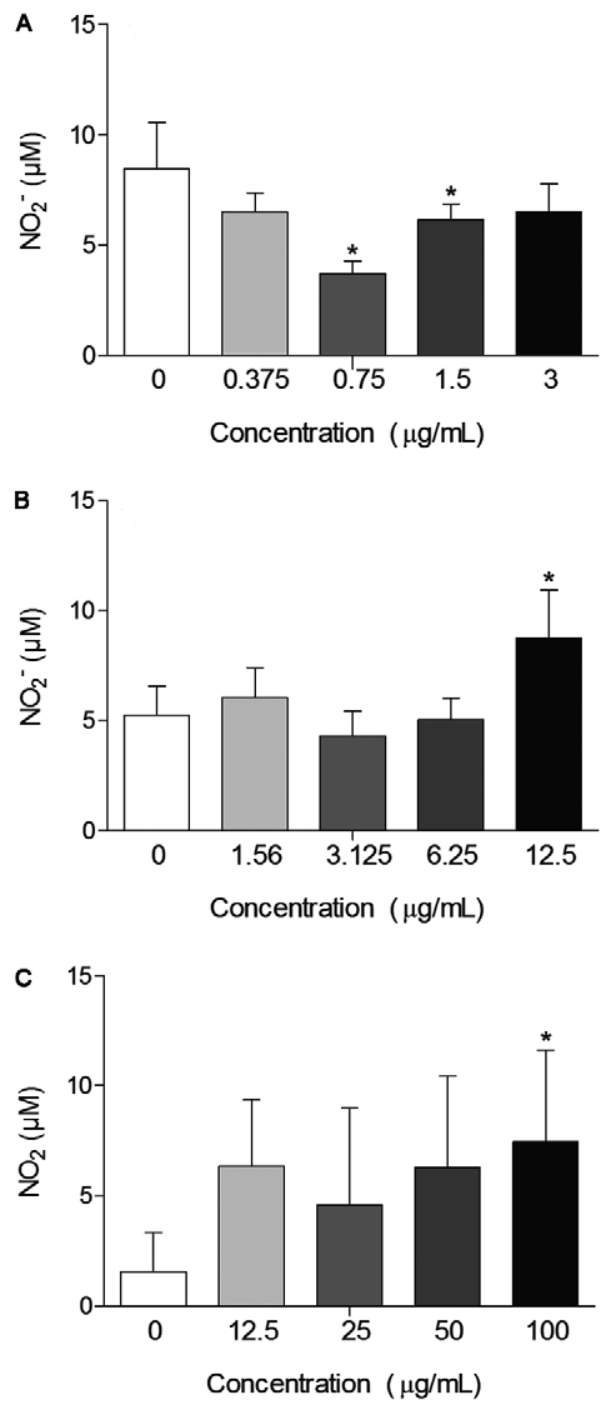

Fig. 5: nitric oxide release by L. amazonensis infected macrophages $72 \mathrm{~h}$ after treatment with hydroethanolic extract from Selaginella sellowii (A), amentoflavone (B) and robustaflavone (C). Bars represent the mean \pm standard deviation of six replicates. $p<0.05(*)$ for the different concentrations compared to untreated cells (Student's $t$ test).

This is the first phytochemical investigation of $S$. sellowii. The fractionation of active SSHE allowed the identification of even more active compounds. The antileishmanial mechanism of amentoflavone does not seem to involve macrophage activation by increasing the release of NO, unlike the mechanism from robustaflavone, which induced an increase in its production. $S$. sellowii may be a potential source of biflavonoids that could provide promising compounds for the treatment of cutaneous leishmaniasis.

\section{REFERENCES}

Agrawal PK, Bansal MC 1989. Other Flavonoids. In PK Agrawal, Carbon-13 NMR of flavonoids. Studies in organic chemistry-39, Elsevier, Amsterdam, p. 236-282.

Assis ELM, Labiak PH 2009. Lycophyta da borda oeste do Pantanal, Mato Grosso do Sul, Brasil. Acta Bot Bras 23: 703-712. 
Banerjee T, Van der Vliet A, Ziboh VA 2002. Downregulation of COX-2 and iNOS by amentoflavone and quercetin in A549 human lung adenocarcinoma cell line. Prostaglandins Leukot Essent Fatty Acids 66: 485-492.

Brahmachari G 2011. Natural products in drug discovery: impacts and opportunities - an assessment. In G Brahmachari, Bioactive natural products: opportunities and challenges in medicinal chemistry, 1st ed., World Scientific Publishing Co. Pte. Ltd., Singapore, p. 1-199.

Camacho MR, Mata R, Castaneda P, Kirby GC, Warhurst DC, Croft SL, Phillipson JD 2000. Bioactive compounds from Celaenodendron mexicanum. Planta Med 66: 463-468.

Claudino VD, da Silva KC, Filho VC, Yunes RA, Monache FD, Giménez A, Salamanca E, Gutierrez-Yapu D, Malheiros A 2013. Drimanes from Drimys brasiliensis with leishmanicidal and antimalarial activity. Mem Inst Oswaldo Cruz 108: 140-144.

Coulerie P, Nour M, Maciuk A, Eydoux C, Guillemot JC, Lebouvier N, Hnawia E, Leblanc K, Lewin G, Canard B, Figadère B 2013. Structure-activity relationship study of biflavonoids on the dengue virus polymerase DENV-NS5 RdRp. Planta Med 79: 1313-1318.

Croft SL, Coombs GH 2003. Leishmaniasis - current chemotherapy and recent advances in the search for novel drugs. Trends Parasitol 19: 502-508.

Ding AH, Nathan CF, Stuer DJ 1988. Release of reactive nitrogen intermediates and reactive oxygen intermediates from mouse peritoneal macrophages: comparison of activating cytokines and evidence for independent production. J Immunol 141: 2407-2412.

Freitas-Júnior LH, Chatelain E, Kim HA, Siqueira-Neto JL 2012. Visceral leishmaniasis treatment: what do we have, what do we need and how to deliver it? Int J Parasitol Drugs Drug Resist 2: 11-19.

Giudice A, Camada I, Leopoldo PTG, Pereira JMB, Riley LW, Wilson ME, Ho JL, Jesus AR, Carvalho EM, Almeida RP 2007. Resistance of Leishmania (Leishmania) amazonensis and Leishmania (Viannia) braziliensis to nitric oxide correlates with disease severity in tegumentary leishmaniasis. BMC Infect Dis 7: 7 .

Gontijo B, Carvalho MLR 2003. Leishmaniose tegumentar americana. Rev Soc Bras Med Trop 36: 71-80.

Grimaldi Jr G, Tesh RB 1993. Leishmaniases of the New World: current concepts and implications for future research. Clin Microbiol Rev 6: $230-250$.

Jeremy AC 1990. Selaginellaceae. In KU Kramer, K Kubitzki, PS Green, The families and genera of vascular plants: pteridophytes and gymnosperms, vol. 1, Springer Verlag, Berlin, p. 39-45.

Jung HJ, Sung WS, Yeo SH, Kim HS, Lee IS, Woo ER, Lee DG 2006. Antifungal effect of amentoflavone derived from Selaginella tamariscina. Arch Pharm Res 29: 746-751.

Kunert O, Swamy RC, Kaiser M, Presser A, Buzzi S, Apparao AVN, Schühly W 2008. Antiplasmodial and leishmanicidal activity of biflavonoids from Indian Selaginella bryopteris. Phytochem Lett 1: 171-174.

Lenta B, Vonthron-Sénécheau C, Soh RF, Tantangmo F, Ngouela S, Kaiser M, Tsamod E, Anton R, Weniger B 2007. In vitro antiprotozoal activities and cytotoxicity of some selected Cameroonian medicinal plants. J Ethnopharmacol 111: 8-12.

Lin LC, Kuo YC, Chou CJ 2000. Cytotoxic biflavonoids from Selaginella delicatula. J Nat Prod 63: 627-630.

Lin RC, Skaltsounis AL, Seguin E, Tillequin F, Koch M 1994. Phenolic constituents of Selaginella doederleinii. Planta Med 60: 168-170.

Ma SC, But PPH, Ooi VEC, He YH, Lee SHS, Lee SF, Lin RC 2001. Antiviral amentoflavone from Selaginella sinensis. Biol Pharm Bull 24: 311-312.
Mabry TJ, Markham KR, Thomas MB 1970. The systematic identification of flavonoids, Springer, New York, 354 pp.

Medeiros MGF, Silva AC, Citó AMGL, Borges AR, Lima SG, Lopes JAD, Figueiredo RCBQ 2011. In vitro antileishmanial activity and cytotoxicity of essential oil from Lippia sidoides Cham. Parasitol Int 60: 237-241.

Mishra PK, Raghuram GV, Bhargava A, Ahirwar A, Samarth R, Upadhyaya R, Jain KS, Pathak N 2011. In vitro and in vivo evaluation of the anticarcinogenic and cancer chemopreventive potential of a flavonoid-rich fraction from a traditional Indian herb Selaginella bryopteris. Br J Nutr 106: 1154-1168.

Monks A, Scudiero D, Skehan P, Shoemaker R, Pau K, Vistica D, Hose C, Langley J, Cronise P 1991. Feasibility of a high-flux anticancer drug screen using a diverse panel of cultured human tumor cell lines. J Natl Cancer Inst 83: 757-766.

Monzote L 2009. Current treatment of leishmaniasis: a review. Int $J$ Antimicrob Agents 1: 9-19.

Oh J, Rho HS, Yang Y, Yoon JY, Lee J, Hong YD, Kim HC, Choi SS, Kim TW, Shin SS, Cho JY 2013. Extracellular signal-regulated kinase is a direct target of the anti-inflammatory compound amentoflavone derived from Torreya nucifera. Mediators Inflamm 2013: 1-11.

Oliveira LFO, Schubach AO, Martins MM, Passos SL, Oliveira RO, Marzochi MC, Andrade CA 2011. Systematic review of the adverse effects of cutaneous leishmaniasis treatment in the New World. Acta Trop 118: 87-96.

Oubada A, García M, Bello-Alarcó A, Cuesta-Rubio O, Monzote L 2014. Antileishmanial activity of leaf extract from Calophyllum rivulare against Leishmania amazonensis. Emir J Food Agric 26: 807-812.

Paladi CS, Pimentel IAS, Katz S, Cunha RLOR, Judice WAS, Caires ACF, Barbiéri CL 2012. In vitro and in vivo activity of a palladacycle complex on Leishmania (Leishmania) amazonensis. PLoS Negl Trop Dis 6: e1626.

Reithinger R, Dujardin JD, Louzir H, Pirmez C, Alexander B, Brooker S 2007. Cutaneous leishmaniasis. Lancet Infect Dis 7: 581-596.

Sah NK, Singh SNP, Sahdev S, Banerji S, Jha V, Khan Z, Hasnain SE 2005. Indian herb 'Sanjeevani' (Selaginella bryopteris) can promote growth and protect against heat shock and apoptotic activities of ultra violet and oxidative stress. J Biosci 30: 499-505.

Sakthivel KM, Guruvayoorappan C 2013. Amentoflavone inhibits iNOS, COX-2 expression and modulates cytokine profile, NF- $\mathrm{kB}$ signal transduction pathways in rats with ulcerative colitis. Int Immunopharmacol 17: 907-916.

Santos JFL, Pagani E, Ramos J, Rodrigues E 2012. Observations on the therapeutic practices of riverine communities of the Unini River, AM, Brazil. J Ethnopharmacol 142: 503-515.

Silverstein RM, Webster FX, Kiemle DJ 2007. Identificação espectrométrica de compostos orgânicos, 7th ed., LTC, Rio de Janeiro, $490 \mathrm{pp}$.

Skehan P, Storeng R, Scudiero D, Monks A, Mcmahon J, Vistica D, Warren JT, Bokesch H, Kenney S, Boyd MR 1990. New colorimetric cytotoxicity assay for anticancer-drug screening. $J$ Natl Cancer Inst 82: 1107-1112.

Sundar S, Chatterjee M 2006. Visceral leishmaniasis - current therapeutic modalities. Indian J Med Res 123: 345-352.

Sundar S, More DK, Singh MK, Singh VP, Sharma S, Makharia A, Kumar PC, Murray HW 2000. Failure of pentavalent antimony in visceral leishmaniasis in India: report from the center of the Indian epidemic. Clin Infect Dis 31: 1104-1107.

Wang YH, Long CL, Yang FM, Wang X, Sun QY, Wang HS, Shi YN, 
Tang GH 2009. Pyrrolidinoindoline alkaloids from Selaginella moellendorfii. J Nat Prod 72: 1151-1154.

Weniger B, Vonthron-Sénécheau C, Kaiser M, Brun R, Anton R 2006. Comparative antiplasmodial, leishmanicidal and antitrypanosomal activities of several biflavonoids. Phytomedicine 13: 176-180.

Woo ER, Lee JY, Cho IJ, Kim SG, Kang KW 2005. Amentoflavone inhibits the induction of nitric oxide synthase by inhibiting NF$\kappa \mathrm{B}$ activation in macrophages. Pharmacol Res 51: 539-546.

Xu GH, Ryoo IJ, Kim YH, Choo SJ, Yoo ID 2009. Free radical scavenging and antielastase activities of flavonoids from the fruits of Thuja orientalis. Arch Pharm Res 32: 275-282.

Yang JW, Pokharel YR, Kim MR, Woo ER, Choi HK, Kang KW 2006.
Inhibition of inducible nitric oxide synthase by sumaflavone isolated from Selaginella tamariscina. J Ethnopharmacol 105: 107-113.

Zembower DE, Lin YM, Flavin MT, Chen FC, Korba BE 1998. Robustaflavone, apotential non-nucleoside anti-hepatitis B agent. Antiviral Res 39: 81-88.

Zhang YX, Li QY, Yan LL, Shi Y 2011. Structural characterization and identification of biflavones in Selaginella tamariscina by liquid chromatography-diode-array detection/electrospray ionization tandem mass spectrometry. Rapid Commun Mass Spectrom 25: 2173-2186.

Zheng XK, Li YJ, Zhang L, Feng WS, Zhang X 2011. Antihyperglycemic activity of Selaginella tamariscina (Beauv.) Spring. $J$ Ethnopharmacol 133: 531-537. 